\title{
Elucidating Pt-based Nanocomposite Catalysts for the Oxygen Reduction Reaction in Rotating Disk Electrode and Gas Diffusion Electrode measurements
}

Jia Du ${ }^{\mathrm{a}}$, Jonathan Quinson ${ }^{\mathrm{b}}$, Alessandro Zana $^{\mathrm{a}}$, Matthias Arenz ${ }^{\mathrm{a} *}$

${ }^{a}$ Department of Chemistry and Biochemistry, University of Bern, Freiestrasse 3, 3012 Bern, Switzerland

${ }^{\mathrm{b}}$ Department of Chemistry, University of Copenhagen, Universitetsparken 5, 2100

Copenhagen $\emptyset$, Denmark

* corresponding author: matthias.arenz@dcb.unibe.ch

\begin{abstract}
In the present study we compare different nanoparticle (NP) composites (nanocomposites) as potential electrocatalysts for the oxygen reduction reaction (ORR). The nanocomposites consist of a mixture of Pt and Ir NPs and Pt and Au NPs, respectively, that are immobilized onto a high surface area carbon support. Pt NPs supported on the same carbon support serve as benchmark. The performance testing was performed in a conventional rotating disk electrode (RDE) setup as well as in a recently introduced gas diffusion electrode (GDE) setup providing high mass transport conditions. The ORR activity is determined, and the degradation tested using accelerated degradation tests (ADTs). It is shown that with respect to the benchmark, the $\mathrm{Pt}-$ Au nanocomposite concept exhibits improved ORR activity as well as improved stability both in the RDE and the GDE measurements. By comparison, the Pt - Ir nanocomposite exhibits improved stability but lower ORR activity. Combining the GDE approach with small angle Xray scattering, it is shown that the improved stability of the $\mathrm{Pt}-\mathrm{Au}$ nanocomposite can be assigned to a reduced Pt particle growth due to the adjacent Au NPs. The results demonstrate
\end{abstract}


that nanocomposites could be an alternative catalyst design strategy complementing the stateof-the-art alloying concepts.

\section{Keywords}

nanocomposite electrocatalysts; oxygen reduction reaction; gas diffusion electrode setup; accelerated degradation tests; small angle X-ray scattering;

\section{Introduction}

Due to its importance for fuel cells, the oxygen reduction reaction (ORR) is one of the most studied reactions in electrocatalysis. Independent if a fuel cell is operated with hydrogen or liquid fuels such as methanol, operates under acidic or alkaline conditions, a substantial part of its performance loss (as compared to the thermodynamic cell potential) is due to the sluggish ORR at its cathode catalyst. In acidic proton exchange membrane fuel cells (PEMFCs), stateof-the-art ORR catalysts are based on Pt-alloy catalysts ${ }^{1-5}$, e.g., PtCo nanoparticles (NPs) supported on a high surface area carbon support. The "kinetic activity" of the ORR catalyst has direct consequences for the conversion efficiency, however, catalyst stability and performance under high mass transport conditions (high current densities) are equally important properties a "good ORR catalyst" must fulfill. Most research concerning Pt-based ORR catalysts for PEMFCs is concerned with an accurate control and optimization of the active Pt phase at the atomic level that determines the kinetics. Substantial achievements have been reported for the initial kinetic activity that need to be sustained under operation conditions. One of most imminent challenges thereby is the changing reaction environment, i.e., going from reductive conditions during operation to slightly oxidizing at open circuit (idling) conditions to (if not prevented) highly oxidizing conditions during start-up and shutdown. Such dynamic conditions not only lead to the dissolution of Pt, they also induce segregation and dissolution of less noble components in Pt-alloys ${ }^{6}$. 
An alternative approach that has been recently introduced is to concentrate on a statistical distribution of surface sites in high entropy alloy (HEA) catalysts with the goal of optimizing the likelihood for highly active surface sites ${ }^{7}$. As compared to conventional bimetallic or trimetallic Pt-based catalysts, the HEA approach is less mature and to date more of fundamental interest. Not only is the synthesis of nanomaterials with random surface arrangements of the different constituents is extremely difficult, also characterizing and maintaining the surface composition is challenging.

By comparison, the synthesis of monometallic nanomaterials is considerably more straightforward. In the presented work, we therefore pursue the concept of composite catalysts consisting of different monometallic NPs, i.e., nanocomposite catalysts, that is currently of primarily fundamental interest as well. The main difference to the established alloying concept is to focus - in addition to the atomic structure - on mesoscopic properties such as the particle density on the support, i.e., the interparticle distance ${ }^{8-11}$. As stated above, in addition to the kinetic performance, the effective mass transport of reactant and product in the catalyst layer are equally crucial to optimize the power density, e.g. for mobile applications of PEMFCs. For this, non-active NP components could for example be used to optimize the catalyst performance without inhibiting the dispersion of the active sites as well as the oxygen mass transport resistance; the latter is often a problem for high performing alloy catalysts that tend to exhibit large particle size and associated large oxygen transport resistance ${ }^{12}$. To investigate the promising nanocomposite concept further, we chose to investigate two different nanocomposite catalysts, i.e., a nanocomposite consisting of carbon supported Pt and activated (oxidized) Ir NPs and a nanocomposite consisting of carbon supported Pt and Au NPs, in the following referred to as $\mathrm{Pt}-\mathrm{IrO}_{2} / \mathrm{C}$ and $\mathrm{Pt}-\mathrm{Au} / \mathrm{C}$. A standard Pt/C catalyst serves as benchmark ${ }^{13,14}$. In Ptbased alloy catalysts, both the addition of $\mathrm{Ir}$ and $\mathrm{Au}$ is reported to improve the ORR performance ${ }^{15,16}$. The performance of the nanocomposite catalysts is investigated in 
conventional rotating disk electrode (RDE) measurements ${ }^{13,17,18}$ as well as in recently introduced gas diffusion electrode (GDE) measurements ${ }^{19-25}$ that in contrast to the RDE measurements provide realistic catalyst loadings as well as realistic mass transport conditions. In addition to the activity, the degradation was tested using accelerated degradation tests (ADTs). It is shown that both nanocomposites, i.e., $\mathrm{Pt}-\mathrm{IrO}_{2} / \mathrm{C}$ and $\mathrm{Pt}-\mathrm{Au} / \mathrm{C}$ exhibit improved degradation resistance, however only in the case of Pt-Au/C the ORR activity is improved as well.

\section{Experimental}

\section{Chemicals and gases}

The following chemicals were used for catalyst synthesis and characterization: hexachloroplatinic (IV) acid hexahydrate $\left(\mathrm{H}_{2} \mathrm{PtCl}_{6} \cdot 6 \mathrm{H}_{2} \mathrm{O}, 99.9 \%\right.$, Alfa Aesar), iridium (III) chloride $\left(\mathrm{IrCl}_{3} \cdot \mathrm{xH}_{2} \mathrm{O},>99.8 \%\right.$, Sigma Aldrich), gold (III) chloride $\left(\mathrm{AuCl}_{3}, \geq 99.99 \%\right.$ trace metals basis, Sigma Aldrich), ethylene glycol (EG, 99.8\%, Sigma Aldrich), sodium hydroxide (NaOH, 98.9\%, Fisher Chemical), oleylamine (technical grade, 70\%, Sigma Aldrich), 1-octadecene (technical grade, 90\%, Sigma Aldrich), lithium triethylborohydride ( $\mathrm{LiBEt}_{3} \mathrm{H}$, super-hydride solution, $1 \mathrm{M}$ in THF, Sigma Aldrich), 30\% hydrochloric acid ( $\mathrm{HCl}$, Suprapur, Merck) and acetone (99.5+\%, Alfa Aesar). Commercial carbon black, Vulcan XC72R was employed as carbon support in the catalyst synthesis. Ultrapure water (resistivity $>18.2 \mathrm{M} \Omega \cdot \mathrm{cm}$, total organic carbon (TOC) <5 ppb) from a Milli-Q system (Millipore) was used for acid/base dilutions, catalyst ink formulation, and electrochemical cell cleaning. Isopropanol (IPA, 99.7+\%, Alfa Aesar), $70 \%$ perchloric acid $\left(\mathrm{HClO}_{4}\right.$, Suprapur, Merck), potassium hydroxide hydrate $\left(\mathrm{KOH} \cdot \mathrm{H}_{2} \mathrm{O}\right.$, Suprapur, Merck) were used for the catalyst ink formulation and electrolyte preparation. The following gases from Air Liquide were used for electrochemical measurements: $\mathrm{Ar}(99.999 \%), \mathrm{O}_{2}(99.999 \%)$, and CO (99.97\%). 
Synthesis of monometallic Pt/C, Pt-IrO$/ C$ nanocomposite, and Pt-Au/C nanocomposite catalysts

The synthesis approach followed a colloidal approach and consists of two main steps: the synthesis of colloidal NPs and their immobilization on a carbon support. Concerning the synthesis of carbon supported monometallic Pt NPs and Pt-IrO $\mathrm{I}_{2}$ nanocomposite catalysts, we applied a surfactant-free colloidal approach ${ }^{26}$ and refer to our recent work ${ }^{27}$. In short, mixing $400 \mathrm{mM}$ of $\mathrm{NaOH}$ EG with $40 \mathrm{mM}$ of $\mathrm{H}_{2} \mathrm{PtCl}_{6} \cdot 6 \mathrm{H}_{2} \mathrm{O}$ or $\mathrm{IrCl}_{3} \cdot \mathrm{xH}_{2} \mathrm{O}$ EG solution in a microwave reaction vessel and heating the mixture to $160{ }^{\circ} \mathrm{C}$ for 3 minutes in a microwave reactor leads to the formation of colloidal Pt or Ir NPs in EG with a concentration of $3.90 \mathrm{~g}_{\mathrm{Pt}} \mathrm{L}^{-1}$ and $3.85 \mathrm{~g}_{\mathrm{Ir}} \mathrm{L}^{-}$ ${ }^{1}$, respectively. To immobilize the NPs on the carbon support, $1 \mathrm{M} \mathrm{HCl}$ was added to the colloidal NPs inducing particle flocculation. The mixture was thereafter centrifuged at 5000 rpm for 10 minutes, the supernatant discarded, and the floc re-dispersed in acetone to obtain a NP dispersion in acetone with the same concentration as before the flocculation in EG. To prepare a monometallic $\mathrm{Pt} / \mathrm{C}$ catalyst, the carbon support (Vulcan $\mathrm{XC72R}$ ) suspension was prepared with a concentration of $0.50 \mathrm{~g} \mathrm{~L}^{-1}$ in acetone and homogenized by a horn sonicator (QSONICA sonicator, $500 \mathrm{~W}, 50 \mathrm{kHz}$, with alternation of 1 second sonication and 1 second resting) for 5 minutes. Then the Pt NPs dispersed in acetone were added and further sonicated for 5 minutes. After the homogenization of the mixture the solvent was evaporated with a rotary evaporator at room temperature and 200 mbar applying a continuous sonication until the catalyst was completely dried and $20 \mathrm{wt} . \% \mathrm{Pt} / \mathrm{C}$ was obtained. A similar procedure was employed to obtain the immobilized $\mathrm{Pt}-\mathrm{IrO}_{2} / \mathrm{C}$ nanocomposite catalyst. Here, Pt NPs dispersed in acetone and Ir NPs dispersed in acetone were added to the sonicated carbon acetone suspension one by one, whereafter the same procedure was applied. The nominal Pt to Ir metal ratio in the nanocomposite was 1: 2 based on weight. The Pt loading was kept as in the benchmark, i.e., 20 wt. \%. 
Concerning the preparation of supported Pt-Au/C nanocomposite catalysts, we applied the same approach for obtaining surfactant-free colloidal Pt NPs. However, for the preparation of Au NPs we used the method reported previously by Zhang et al. ${ }^{28}$. In short, $\mathrm{AuCl}_{3}(151.7 \mathrm{mg})$ was dissolved in a mixture of 1-octadecene $(16 \mathrm{~mL})$ and oleylamine $(4 \mathrm{~mL})$ under Ar atmosphere. The system was protected by $\mathrm{Ar}$ atmosphere and heated to $60^{\circ} \mathrm{C}$, followed by a quick injection of the reducing agent $\mathrm{LiBEt}_{3} \mathrm{H}(1.5 \mathrm{~mL})$. Keeping at $60{ }^{\circ} \mathrm{C}$ for 10 minutes, whereafter the solution was cooled down to room temperature. Thereafter, the system was exposed to air, and ethanol was added to separate Au NPs with centrifugation at $5000 \mathrm{rpm}$ for 10 minutes. The asprepared Au NPs were re-dispersed in hexane at a concentration of $0.82 \mathrm{~g}_{\mathrm{Au}} \mathrm{L}^{-1}$. To immobilize the monometallic Au NPs, carbon was dispersed in hexane and sonicated with the horn sonicator as mentioned above until a stable dispersion was obtained ( 10 minutes). Then the $\mathrm{Au}$ NPs dispersed in hexane were added and the suspension was sonicated further for 10 minutes and thereafter hexane was evaporated with a rotary evaporator until the catalyst was completely dried obtaining $40 \mathrm{wt} \% \mathrm{Au} / \mathrm{C}$. To remove the ligand (oleylamine) the dried Au/C powder was heated in an oven (Nabertherm, 30-3000 ${ }^{\circ} \mathrm{C}$ ) at $210{ }^{\circ} \mathrm{C}$ for 5 hours. If the ligand is not removed from the Au surface, $\mathrm{Au} / \mathrm{C}$ cannot be dispersed in acetone, which will inevitably influence the subsequent immobilization step of the Pt NPs (that were dispersed in acetone after flocculation with $1 \mathrm{M} \mathrm{HCl}$ ) onto the $\mathrm{Au} / \mathrm{C}$. Another point needs to be noted: to obtain the carbon supported Pt-IrO $\mathrm{I}_{2}$ nanocomposite, the Pt NPs and Ir NPs were added one by one to the carbon suspension in acetone. In the procedure of the carbon supported Pt-Au nanocomposite, instead of adding Pt NPs and Au NPs simultaneously during the immobilization procedure, first $\mathrm{Au} / \mathrm{C}$ was obtained which may have suffered from the thermal treatment for ligand removing. The Pt NPs were immobilized on the ligand-free $\mathrm{Au} / \mathrm{C}$, to avoid exposing the Pt NPs to the thermal treatment which may induce the complete oxidation of Pt. The immobilization procedure of the Pt NPs on the ligand-free $\mathrm{Au} / \mathrm{C}$ followed the same procedure as described above, i.e., mixing, 
sonication and solvent evaporation. The prepared Pt-Au/C nanocomposite had a nominal Pt to Au metal weight ratio of 1:2 and a Pt loading of $20 \mathrm{wt} . \%$.

\section{Catalyst ink formation and catalyst layer preparation for RDE measurements}

To obtain inks for the RDE measurements the respective dried catalyst powder was dispersed in a mixture of Milli-Q water and IPA ( $\mathrm{V}_{\text {water: }}$ V $\left.\mathrm{V}_{\mathrm{IPA}}=3: 1\right)$ containing $1.6 \mu \mathrm{L} / \mathrm{ml} 1 \mathrm{M} \mathrm{KOH}(\mathrm{aq})$ ${ }^{17}$ and homogenized in a sonicator bath for 10 minutes resulting in a homogeneous catalyst ink with a total Pt concentration of $0.275 \mathrm{~g} \mathrm{~L}^{-1}$. Pipetting $7.14 \mu \mathrm{L}$ of the respective catalyst ink onto glassy carbon (GC) disks to obtain a fixed Pt loading of $10 \mu \mathrm{g} \mathrm{cm}^{-2}$ Geo for all samples. The GC tips were dried at ambient atmosphere for further electrochemical measurements. Conducting cyclic voltammograms $(\mathrm{CV})$ between $0.05-1.60 \mathrm{~V}_{\mathrm{RHE}}$, the appearance of the broad oxidation peak (centered at around $1.40 \mathrm{~V}_{\mathrm{RHE}}$ ) as well as the oxide reduction peak (centered at around 1.20 $\left.\mathrm{V}_{\mathrm{RHE}}\right)$ can be the indication of the presence of $\mathrm{Au}$ in the catalyst, see Figure $\mathrm{S} 1$. The $\mathrm{Pt}$ weight loading on carbon support in the mentioned electrocatalysts thereby is fixed to $20 \mathrm{wt}$. $\%$.

\section{Gas diffusion electrode (GDE) cell setup}

An in-house gas diffusion electrode setup as described before ${ }^{19,22,24,29}$ was used in the electrochemical measurements. A GDE setup with a lower cell body made of stainless steel and a flow field was used. The GDE was placed above the flow field with a Nafion membrane (Nafion 117, $183 \mu \mathrm{m}$ thick, Fuel Cell Store) facing upwards. The upper cell body was made of polytetrafluoroethylene (PTFE). A platinum mesh and a reversible hydrogen electrode (RHE) were used as a counter electrode and a reference electrode, respectively. The counter electrode was placed inside a glass capillary tube with a glass frit on the bottom, which can avoid the trapping of gas bubbles in the hole of the Teflon cell and hence improves the reproducibility of the measurements. 


\section{Catalyst ink formation and catalyst layer preparation for GDE}

The recipe of the catalyst ink for the GDE measurements was reported previously ${ }^{24}$.The catalyst ink was formed by dispersing the catalysts in a mixture of Milli-Q water and IPA ( $\mathrm{V}_{\text {water }}: \mathrm{V}_{\mathrm{IPA}}=3: 1$ ) to obtain the concentration of Pt is $0.50 \mathrm{~g} \mathrm{~L}^{-1}$. Nafion (D1021, 10 wt. \%, Fuel Cell Store) was added to the catalyst ink in a weight ratio between Nafion and carbon of 1 . Then the solution was sonicated in a sonication bath for around 5 minutes to obtain a stable dispersion.

A H23C8 gas diffusion layer (GDL) was punched from a larger GDL sheet and placed into a vacuum filtration setup between a glass funnel and a sand core filter. All this was placed on the top of a collecting bottle as reported by Yarlagadda et al. ${ }^{30}$. Separate vacuum filtration setups were used for the $\mathrm{Pt}-\mathrm{IrO}_{2} / \mathrm{C}$ and $\mathrm{Pt}-\mathrm{Au} / \mathrm{C}$ nanocomposite catalysts to avoid cross-contamination. For the Pt-IrO $/ 2$ C nanocomposite catalyst a setup with a sand core filter of $42 \mathrm{~mm}$ in diameter was used while for monometallic $\mathrm{Pt} / \mathrm{C}$ and the $\mathrm{Pt}-\mathrm{Au} / \mathrm{C}$ nanocomposite catalysts a setup with a sand core filter of $15 \mathrm{~mm}$ in diameter was used. The catalyst ink was diluted from a concentration of $0.50 \mathrm{~g}_{\mathrm{Pt}} \mathrm{L}^{-1}$ to $0.05 \mathrm{~g}_{\mathrm{Pt}} \mathrm{L}^{-1}$ by adding Milli-Q water and IPA (the final volume ratio between Milli-Q water and IPA was 1: 3 to increase the speed of vacuum filtration). The diluted catalyst ink was filled into the funnel and a vacuum pump was used to deposit the catalyst on top of the GDL. With this deposition procedure, in all cases a nominal Pt loading of $208 \mu \mathrm{g} \mathrm{cm}^{-2}$ geo on the GDL was obtained. After preparing the catalyst layer on the GDL, a Nafion membrane was pressed on top of the GDE. For this, a Teflon sheet, a GDL without MPL (Ø $2 \mathrm{~cm}$ ), a GDL with MPL (Ø $2 \mathrm{~cm}$ with hole of $\varnothing 3 \mathrm{~mm}$ ), the catalyst on the GDL from the vacuum filtration (Ø $3 \mathrm{~mm}$ ), a Nafion membrane and the second Teflon sheet were placed in this order one by one on top of a Teflon block. Then a second Teflon block was placed on the top and everything was placed between two metal blocks and pressed at 2 tons for 10 minutes. 
All electrochemical measurements were recorded with a computer controlled potentiostat (ECi 200, Nordic Electrochemistry) at room temperature. The RDE measurements were performed using the same setup employed in our previous work ${ }^{18}$, i.e., in a glass cell equipped with three electrodes. A GC RDE tip with a diameter of $5 \mathrm{~mm}$ was used as working electrode (WE) and a platinum wire as counter electrode (CE). All potentials were measured with respect to a trapped hydrogen reversible hydrogen electrode (RHE) as reference electrode (RE). As aqueous electrolyte $0.1 \mathrm{M} \mathrm{HClO}_{4}$ was used that was saturated with Ar before the electrochemical measurements. For the Pt- $\mathrm{IrO}_{2} / \mathrm{C}$ nanocomposite, the Ir NPs were activated by the holding potential at $1.60 \mathrm{~V}_{\mathrm{RHE}}$ for 8 minutes. After activation, the catalyst was exposed to potential cycling between $0.05 \mathrm{~V}_{\mathrm{RHE}}$ and $1.20 \mathrm{~V}_{\mathrm{RHE}}$ until a stable $\mathrm{CV}$ with the basic features of Pt was observed. For the monometallic $\mathrm{Pt} / \mathrm{C}$ and $\mathrm{Pt}-\mathrm{Au} / \mathrm{C}$ nanocomposite catalysts, the same potential cycling was applied, however, no activation was performed. During the potential cycling, the cell resistance between the WE and $\operatorname{RE}(\sim 25 \Omega)$ was compensated to an effective value of around $3 \Omega$ using the analog positive feedback scheme of the potentiostat.

In the RDE setup, the activity and stability tests were separately conducted, i.e., for each catalyst at least 3 different tips were used for activity measurements and 3 different tips were used for the stability measurements. For the ORR activity measurements, a macro-script was designed with the EC4DAQ potentiostat software to automatically record a series of cyclic voltammograms (CVs), CO stripping curves, and ORR polarization curves ${ }^{18}$. The CVs were recorded in Ar saturated electrolyte in the potential region between $0.05 \mathrm{~V}_{\mathrm{RHE}}$ and $1.10 \mathrm{~V}_{\mathrm{RHE}}$ with a scan rate of $50 \mathrm{mV} \mathrm{s}^{-1}$. For the $\mathrm{CO}$ stripping measurements was employed to determine Pt area, basically, the electrode was held at $0.15 \mathrm{~V}_{\mathrm{RHE}}$ in a $\mathrm{CO}$ saturated electrolyte for 2 minutes. Then the electrolyte was purged with Ar and held at $0.15 \mathrm{~V}_{\mathrm{RHE}}$ for 10 minutes to replace the excess $\mathrm{CO}$ in the electrolyte, the adsorbed $\mathrm{CO}$ monolayer was oxidized to $\mathrm{CO}_{2}$ by cycling the potential from 0.15 to $1.10 \mathrm{~V}_{\mathrm{RHE}}$ at a scan rate of $50 \mathrm{mV} \mathrm{s}^{-1}$. The ECSA (Pt area) 
was calculated based on a reference oxidation charge value from polycrystalline Pt of $396 \mu \mathrm{C}$ $\mathrm{cm}_{\mathrm{Pt}^{-2}}$. For the $\mathrm{Pt}-\mathrm{Ir} / \mathrm{C}$ nanocomposite, as Ir was pre-activated (Ir was oxidized to $\mathrm{IrO}_{2}$ ), the contribution from Ir for ECSA determination is negligible as reported previously ${ }^{31}$. Because the interaction between $\mathrm{CO}$ and the Au surface is quite weak as well, the same is the case for the the Pt-Au/C nanocomposite. To confirm this, we conducted the $\mathrm{CO}$ stripping measurement with pure $\mathrm{Au} / \mathrm{C}$ in which the gold content was the same as $\mathrm{Pt}-\mathrm{Au} / \mathrm{C}$ nanocomposite. The measurement exhibited only a very small the $\mathrm{CO}$ oxidation peak centered at around $1.10 \mathrm{~V}_{\mathrm{RHE}}$ with a calculated surface area below $5 \mathrm{~m}^{2} \mathrm{~g}_{\mathrm{Au}}{ }^{-1}$. The ORR activity measurements were conducted in $\mathrm{O}_{2}$ saturated electrolyte at a scan rate of $50 \mathrm{mV} \mathrm{s}^{-1}$ and a rotation speed of 1600 rpm. The specific activity was normalized by the Pt surface area and compared at $0.85 \mathrm{~V}_{\mathrm{RHE}}$ from the polarization curve recorded in the negative going scan direction (corrected by an background subtraction recorded under inert atmosphere). The mass activity was normalized by the Pt content and compared at $0.85 \mathrm{~V}_{\mathrm{RHE}}$ as well.

To determine the stability of the Pt-based electrocatalysts, accelerated degradation tests (ADT) were employed using four different protocols in the RDE measurements. The first three protocols were performed in a potential control mode in Ar saturated electrolyte. One protocol simulates load cycling conditions, stepping the electrode potential between 0.60 and $1.00 \mathrm{~V}_{\mathrm{RHE}}$ with a rest time of 3 seconds at each potential. The treatment lasted for 9000 cycles. The second protocol simulates start-up/shutdown conditions by cycling the electrode potential between 1.00 and $1.50 \mathrm{~V}_{\mathrm{RHE}}$ with a scan rate of $500 \mathrm{mV} \mathrm{s}^{-1}$; The total treatment lasted for 9000 cycles as well. These protocols are based on the FCCJ recommendations ${ }^{32,33}$. The third protocol was designed of a combination of the above two protocols, cycling the electrode potential between 0.40 and $1.40 \mathrm{~V}_{\mathrm{RHE}}$ with a scan rate of $1000 \mathrm{mV} \mathrm{s}^{-1}$, the total treatment lasted for 3600 cycles ${ }^{34}$. The fourth protocol was performed in current control alternating reductive and oxidative currents and was adapted from our previous stability study of bifunctional ORR - OER catalysts ${ }^{27}$. The 
measurements were conducted in the $\mathrm{O}_{2}$ saturated electrolyte maintaining a rotation of 1600 $\mathrm{rpm}$. The current was stepped between 0 and $-5 \mathrm{~mA} \mathrm{~cm}_{\mathrm{geo}}{ }^{-2}$ with a holding time of 1 second for each current, repeating this cycle for 5 times and followed by a current stepped to $1 \mathrm{~mA} \mathrm{\textrm {cm } _ { \text { geo } } { } ^ { - }}$ ${ }^{2}$ for 1 second. The above procedure was regarded as a basic unit and this unit was repeated for 300 times. Sketches of the different degradation protocols are summarized in Figure S2. The stability of catalysts was evaluated by the change of Pt ECSA that was recorded by CO stripping measurements before and after applying the ADT protocols.

For the electrochemical measurements in the GDE setup $4 \mathrm{M} \mathrm{HClO}_{4}$ was used as electrolyte in the upper compartment above the Nafion membrane ${ }^{22}$. Prior to the electrochemical measurements, the electrode was purged with $\mathrm{Ar}$ gas, and the catalyst $(\mathrm{Pt} / \mathrm{C}$ and $\mathrm{Pt}-\mathrm{Au} / \mathrm{C}$ nanocomposite) was cleaned by potential cycling between $0.05 \mathrm{~V}_{\mathrm{RHE}}$ and $1.20 \mathrm{~V}_{\mathrm{RHE}}$ until a stable CV with the basic features of $\mathrm{Pt}$ was observed ( $\sim 50$ cycles). In case of the Pt-Ir/C nanocomposite, the potential was held at $1.60 \mathrm{~V}_{\mathrm{RHE}}$ for 8 minutes to activate Ir. After the activation procedure, the potential was cycled between $0.10 \mathrm{~V}_{\mathrm{RHE}}$ and $1.20 \mathrm{~V}_{\mathrm{RHE}}$ for further cleaning of the catalyst surface. During the cleaning procedure the resistance between the working and reference electrode $(\sim 10 \Omega)$ was compensated to an effective value of around $1 \Omega$ using the analog positive feedback scheme of the potentiostat.

The ORR activity and stability tests of the catalysts were performed with the same catalyst layer. For each catalyst, at least 3 measurements were repeated to obtain an acceptable reproducibility of the data. The automized measurement procedure was applied using a macro-script of the potentiostat software for each catalyst: i.e., CVs, CO stripping, ORR activity determination, ADT treatment, ORR activity determination, CO stripping and CVs. The ORR activity before the ADT treatment is referred to as beginning of treatment (BOT) activity, the one measured after the ADT treatment as end of treatment (EOT) activity. The measurement conditions during the CVs and $\mathrm{CO}$ stripping measurements were the same as those in the RDE measurements 
described above. To establish the ORR activity in a GDE setup, it is not ideal to sweep the electrode potential as done in RDE measurements as the high current densities lead to considerable $\mathrm{iR}$ drops even if a compensation is used. This does not only distort the potential but also the scan speed. Therefore, we adopted a protocol introduced by Pinaud et al. ${ }^{20,21}$ using steady state measurements in current control mode (galvanostatic). The current was stepwise increased, i.e.: $-1 \mathrm{~mA} \mathrm{~cm}_{\mathrm{geo}^{-2}},-10 \mathrm{~mA} \mathrm{~cm}_{\text {geo }^{-2}},-100 \mathrm{~mA} \mathrm{~cm}_{\text {geo }}{ }^{-2},-500 \mathrm{~mA} \mathrm{~cm}$ geo $^{-2},-1000 \mathrm{~mA}$ $\mathrm{cm}_{\mathrm{geo}}{ }^{-2}$, and $-1500 \mathrm{~mA} \mathrm{~cm} \mathrm{geo}^{-2}$, with a hold time of 30 seconds each. As ORR performance, the working electrode potential at each current density was averaged over the last 5 seconds of the current hold. Despite the $\mathrm{iR}$ was compensated to a value around $1 \Omega$, a post measurement resistance correction is necessary for each current to obtain the correct electrode potential, i.e., the residual solution resistance was recorded online using the AC signal $(5 \mathrm{kHz}, 5 \mathrm{mV})$ and the formula of $E_{\text {real }}=E_{\text {measured }}-i R_{u}$ was applied to obtain the real working electrode potential. After the ADT treatment, the same ORR measurement protocol was employed ones more to compare the ECSA loss with the ORR activity loss. The ADT treatment was adopted for the GDE setup 35 and consisted of a combination of simulating load cycling conditions and start-up/shutdown conditions. For this the electrode potential was stepped 25 times between 0.60 and $1.00 \mathrm{~V}_{\mathrm{RHE}}$ (the hold time for each potential was 3 seconds) followed by two potential cycles between 1.00 and $1.50 \mathrm{~V}_{\mathrm{RHE}}$ at a scan rate of $500 \mathrm{mV} \mathrm{s}^{-1}$. The treatment was performed in $\mathrm{O}_{2}$ atmosphere and repeated 20 times. A scheme of the degradation protocol is shown in Figure S2. The Pt surface area was determined by $\mathrm{CO}$ stripping measurements (as listed in the macro-script) before and after degradation test to evaluate the stability of each catalyst.

Transmission electron microscopy (TEM) and energy dispersive X-ray spectroscopy (EDX)

A Jeol 2100 transmission electron microscope operated at $200 \mathrm{kV}$ and equipped with an EDX detector was used for the TEM analysis. The samples before electrochemical treatment were prepared by suspending the catalyst powder in ethanol and dropping the mixture onto carbon 
coated copper TEM grids (Quantifoil). The samples after the electrochemical treatments were collected from the rotating disk electrode (RDE) and dissolved in acetone for the preparation of TEM grids. Micrographs were recorded at different magnifications (at least x300 000, x400 $000, x 500$ 000) in at least three randomly selected areas. The composition of the samples was evaluated by determining the relative ratio of Ir/Pt and Au/Pt by EDX in at least three different randomly selected areas.

The composition of the supported nanocomposites on the gas diffusion layer (GDL) was evaluated with EDX as well, however recorded in a scanning electron microscope (SEM). For this, the GDL with the filtered nanocomposite on top was put on a sticky carbon tape, which was then put on a SEM metal holder. The analysis was conducted with a Zeiss Gemini 450 SEM equipped with an Oxford Instruments UltimMax 65 EDX detector at a voltage of $25 \mathrm{kV}$. Five independent areas on the GDL were selected for each sample. The software AZtec 4.2 (Oxford Instruments) was used to acquire the EDX spectra and to determine sample composition.

\section{Small angle X-ray scattering (SAXS)}

SAXS measurements were performed at the Niels Bohr Institute at the University of Copenhagen with a SAXSLab instrument as previously detailed ${ }^{24,29,31}$. The instrument is equipped with a 100XL + micro-focus sealed X-ray tube from Rigaku, producing a photon beam with a wavelength of $1.54 \AA$. A 2D 300 K Pilatus detector (Dectris) was used to record the scattering patterns. The two-dimensional scattering data were azimuthally averaged, normalized by the incident radiation intensity, the sample exposure time and the transmission, and then corrected for background and detector inhomogeneities using SAXGUI reduction software. The samples with NPs on GDL were sealed between two mica windows and the background measurement was performed with the same GDL without any NPs. The radially averaged intensity $I(q)$ is expressed as a function of the scattering vector $q=4 \pi \cdot \sin (\theta) / \lambda$, 
where $\lambda$ is the wavelength and $2 \theta$ is the scattering angle. A power law was used for fitting scattering data after background correction, the scattering data was fitted with polydisperse spheres as a model and described by a volume-weighted log-normal distribution. The scattering data are fitted to the expression:

$$
I(q)=A \cdot q^{-n}+C_{1} \cdot \int P_{s 1}(q, R) V_{1}(R) D_{1}(R) d R+C_{2} \cdot \int P_{s 2}(q, R) V_{2}(R) D_{2}(R) d R
$$

where $A \cdot q^{-n}$ is the power law in which $A$ and $n$ are free parameters, $C_{1}$ and $C_{2}$ are scaling constants, $P_{S 1}$ and $P_{S 2}$ are the sphere form factors, $V_{1}$ and $V_{2}$ are the particle volumes, $D_{1}$ and $D_{2}$ are the log-normal size distributions. The sphere form factor is expressed as:

$$
P_{S}(q, R)=\left(3 \frac{\sin (q R)-q R \cos (q R)}{(q R)^{3}}\right)^{2}
$$

and the log-normal distribution is expressed as:

$$
D(R)=\frac{1}{R \sigma \sqrt{2 \pi}} e^{\left(\frac{-\left[\ln \left(\frac{R}{R 0}\right)\right]^{2}}{2 \sigma^{2}}\right)}
$$

The fitting was conducted with a home written MATLAB code. The values obtained for free parameters in the model are listed in Table S1, the corresponding fits are shown in Figure S3.

Ex situ X-ray absorption spectroscopy (XAS)

Ex situ x-ray absorption spectroscopy measurements at the $\mathrm{Pt} \mathrm{L}_{3}$ edge were carried out at the SuperXAS beamline at the Swiss Light Source (Villigen, Switzerland). The incident photon beam provided by a $2.9 \mathrm{~T}$ super bend magnet and collimated by a Rh coated mirror as $2.5 \mathrm{mrad}$. Subsequently the X-ray beam was monochromatised by a Si (111) channel-cut Quick-EXAFS monochromator ${ }^{36}$. The beam was focused by rhodium-coated torroidal mirror with a beam size of approximately $1.0 \mathrm{~mm} \times 0.2 \mathrm{~mm}$ at the sample position. The $\mathrm{Rh}$ coated mirrors also act to 
suppress higher order harmonics. Each sample was measured in transmission geometry for 10 minutes in QEXAFS mode. The acquired data were then processed using ProQEXAFS allowing for energy calibration, interpolation and averaging ${ }^{37}$. The samples for ex situ x-ray absorption spectroscopy measurements were vacuum filtered on GDL, a higher nominal Pt loading of 400 $\mu \mathrm{g} \mathrm{cm}^{-2}$ geo was utilized to obtain sufficient signal from ex situ x-ray absorption spectroscopy measurements.

\section{Results and discussion}

This study aims to investigate nanocomposite materials as potential electrocatalysts for the ORR. For this, we performed measurements with a conventional RDE setup as well as in a GDE setup: the latter is to obtain more applied conditions with realistic catalyst loading, a membrane catalyst interface, and realistic mass transport conditions. Two different nanocomposites were investigated in the current study, i.e., $\mathrm{Pt}-\mathrm{IrO}_{2} / \mathrm{C}$ and Pt-Au/C Pt. 20 wt.\% $\mathrm{Pt} / \mathrm{C}$ serves as benchmark. To achieve comparative results, the active phase in all catalysts, i.e., the Pt loading, was kept at 20 wt.\%. The nominal loading of the second metal component was fixed at $40 \mathrm{wt} . \%$, i.e., the nanocomposite catalysts had the compositions $20 \mathrm{wt} . \% \mathrm{Pt}+40 \mathrm{wt} . \%$ Ir and 20 wt. $\% \mathrm{Pt}+40 \mathrm{wt} . \% \mathrm{Au}$, respectively.

Representative TEM micrographs of the investigated catalysts are presented in Figure 1 together with histograms of their particle size distribution and the probability density of their particle size derived from SAXS measurements. The average particle sizes are also summarized in TableS1 and Table S2. It can be seen that the Pt NPs in the Pt/C benchmark catalyst exhibit an average diameter of $1.7 \pm 0.5 \mathrm{~nm}$ and are homogeneously distributed on the carbon support. By comparison, for the in $\mathrm{Pt}-\mathrm{IrO}_{2} / \mathrm{C}$ nanocomposite it is difficult to distinguish the $\mathrm{Pt}$ and $\mathrm{Ir}$ NPs. All NPs have similar size, but it is apparent that the support is covered more densely. In the size histogram, no clearly distinguishable size populations are apparent. The best fit of the SAXS data, however, leads to two size populations with average sizes of $3.2 \pm 1.7 \mathrm{~nm}$ and 1.2 
$\pm 0.2 \mathrm{~nm}$ which may assigned to Pt and Ir NPs, respectively. However, the larger average size of the Pt NPs as compared to the $\mathrm{Pt} / \mathrm{C}$ reference sample indicates that an unambiguous separation of the size population of the Pt and the Ir NPs is not possible, and that some smaller Pt NPs are accounted for in the "Ir size population". For the Pt-Au/C nanocomposite, the Pt and $\mathrm{Au}$ NPs are clearly distinguishable. Large and small NPs "co-decorate" the carbon support evenly with very few parts with agglomerated NPs. The two size populations are clearly distinguishable in the size histogram as well as the probability density function retrieved from SAXS. The small particles have an average size of $1.7 \pm 0.7 \mathrm{~nm}$ and are thus assigned to Pt NPs. The average size of the larger particles is $9.4 \pm 2.9 \mathrm{~nm}$ and are assigned to Au NPs. The satisfactory dispersion and full utilization of the active Pt NP phase is demonstrated by CO stripping measurements, see Figure S4. The results indicate comparable electrochemically accessible surface areas of Pt for each investigated catalyst independent if investigated by RDE or in the GDE setup; only the $\mathrm{Pt}-\mathrm{IrO}_{2} / \mathrm{C}$ nanocomposite exhibits slightly lower ECSA values. Furthermore, it is seen that the ECSA values determined by RDE tend to be slightly larger than the ones determined in the GDE, which can be explained by the required addition of Nafion to the catalyst inks for the preparation of the GDE layers (without Nafion no proton conduction is established in the catalyst layers); i.e., the Nafion partially blocks the Pt surface leading to lower ECSA values ${ }^{38}$. Last but not least, the EDX analysis of the nanocomposites reveals that the obtained metal compositions with determined wt. ratios of 2.03 and 1.95 for $\mathrm{Ir} / \mathrm{Pt}$ and $\mathrm{Au} / \mathrm{Pt}$ (Table S5), respectively, are close to the targeted value of 2). Thus it can be concluded that the surfactant-free colloidal approach indeed allows for an accurate preparation of different nanocomposite catalysts ${ }^{27}$. 
a)
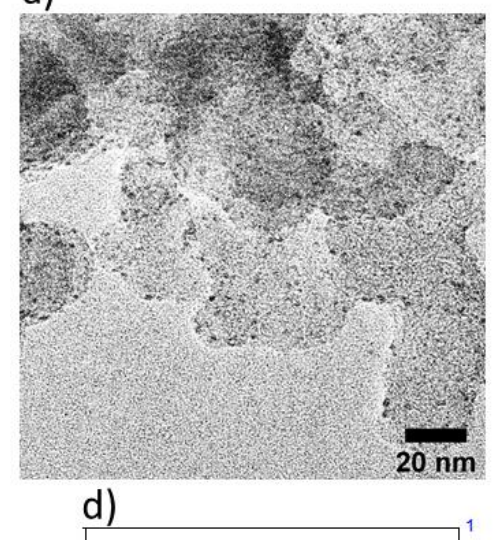

b)

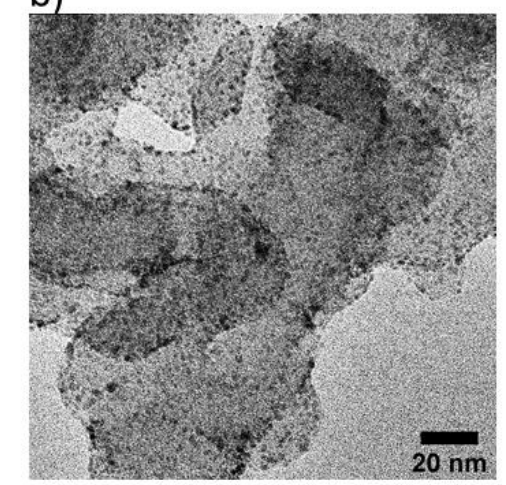

e)

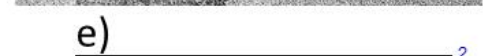

c)
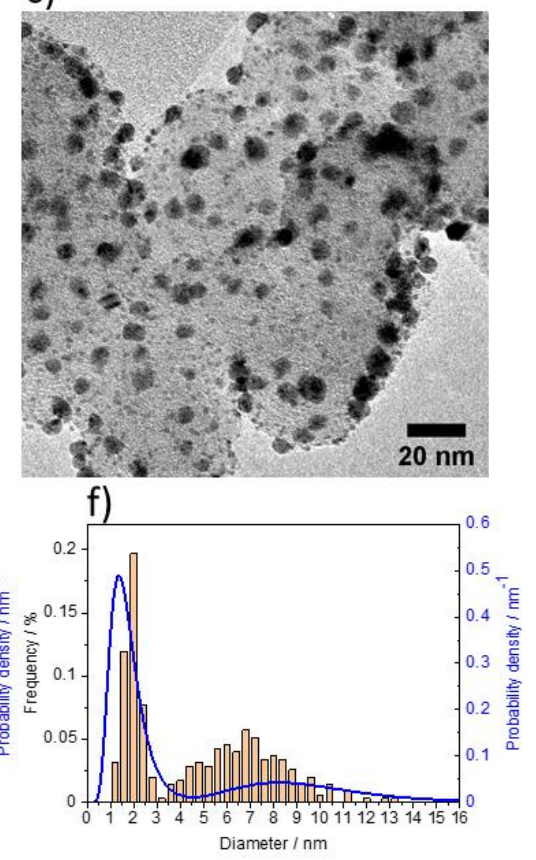

Figure 1. TEM micrographs and size distributions of the investigated catalysts. (a, d) Supported monometallic Pt NPs with a metal loading of $20 \mathrm{wt} \%$, (b, e) Supported nanocomposite with 20 wt.\% Pt NPs, 40 wt.\% Ir NPs (Pt-IrO $/$ C) and (c, f) Supported nanocomposite with $20 \mathrm{wt} . \% \mathrm{Pt}$ NPs, 40 wt.\% Au NPs (Pt-Au/C). The histograms are based on the statistical analysis of 350 individual particles of each as-prepared catalyst from TEM and the volume weighted probability density of the particle size is derived from SAXS measurements.

It is widely accepted that $\mathrm{IrO}_{2}$ is not a good catalyst for the ORR. Au on its own also performs badly for the ORR in acidic conditions, with $\mathrm{H}_{2} \mathrm{O}_{2}$ or $\mathrm{HO}_{2}^{-}$being the final product of the reaction ${ }^{39-41}$. However, in previous studies it was reported that Pt-Au core-shell structures ${ }^{42}, \mathrm{Pt}-\mathrm{Au}$ alloy structures ${ }^{15}$, and Au-modified Pt structures ${ }^{43}$ can not only increase the ORR rate but also the stability. We evaluated the ORR performance of the investigated catalysts both in specific activity (SA) and mass activity (MA), i.e., normalized by Pt surface area and Pt mass, respectively. The polarization curves and Tafel plots (from the positive scan direction) are shown in the supporting information (Figure S5). It is known that the investigation of the ORR performance under transient conditions leads to an overestimation of the activity in comparison to the performance under steady state conditions ${ }^{44-47}$. This leads to a hysteresis between the negative and positive going scan direction ${ }^{48}$ and is also reflected in the higher ORR rates 
determined by RDE as compared to the measurements in the GDE setup. To alleviate this difference, here we determined the ORR activities from the RDE measurements of the polarization curves recorded in negative instead of the typically chosen positive scan direction. In Figure 2, the performance of the different catalysts determined in RDE measurements is summarized. It is seen that the activity trends for SA and MA are identical. The ORR activity is decreased by mixing Ir NPs to a Pt/C catalyst in agreement with our previous study ${ }^{27}$, while the same amount of $\mathrm{Au}$ NPs clearly enhances the ORR performance. For Pt-IrO $\mathrm{I}_{2} / \mathrm{C}$, a SA of $416 \pm 16 \mu \mathrm{A} \mathrm{cmPt}^{-2}$ and a MA activity of $307 \pm 26 \mathrm{~A} \mathrm{~g}_{\mathrm{Pt}}{ }^{-1}$ were determined, see also Table S3, which is less than half of the $\mathrm{Pt} / \mathrm{C}$ benchmark activities, i.e., $915 \pm 58 \mu \mathrm{A} \mathrm{cm}_{\mathrm{Pt}^{-2}}$ and $750 \pm 63 \mathrm{~A} \mathrm{~g}_{\mathrm{Pt}}{ }^{-1}$. On the contrary, for Pt-Au/C, a SA of $1280 \pm 102 \mu \mathrm{A} \mathrm{cmPt}{ }^{-2}$ and a MA of $1060 \pm 71 \mathrm{~A} \mathrm{gPt}^{-1}$ were determined, i.e., around 1.4 times higher than for the benchmark catalyst. The ORR activity of Pt-based catalysts is in general considered to be correlated to the adsorption energies of the $\mathrm{O}^{*}$, $\mathrm{OH}^{*}$, and $\mathrm{OOH}^{*}$ intermediates ${ }^{49}$, here referred to as oxophilicity. In agreement with our previous study ${ }^{27}$, we therefore assume that the reduced ORR activity of the $\mathrm{Pt}-\mathrm{IrO} / \mathrm{C}$ nanocomposite can be ascribed to the more oxophilic nature of Pt NPs adjacent to $\mathrm{IrO}_{2}$ particles. Concurrently, the improved activity of Pt-Au/C suggests that the electronic properties of Pt NPs are affected in a different way (i.e., less oxophilic) by the adjacent Au NPs. To test this hypothesis, we performed ex situ XANES measurement determining the white line (WL) intensity at the $\mathrm{Pt} \mathrm{L}_{3}$ edge, which corresponds closely to the density of unoccupied states and thus the oxidation state of the $\mathrm{Pt}^{50}$. As shown in Figure S6, the Pt-Au/C nanocomposite indeed exhibits lower WL intensity than the Pt/C benchmark, indicating a lower oxophilicity. As a result, the active Pt surface sites in the Pt-Au/C nanocomposite are less blocked by the ORR intermediates than in case on the $\mathrm{Pt} / \mathrm{C}$ benchmark leading to an improved ORR activity. It should be mentioned though that the ex situ determined WL intensity of the non-activated Pt$\mathrm{IrO}_{2} / \mathrm{C}$ nanocomposite is comparable to the one of the Pt/C benchmark (Figure S6) and that for a more detailed study in situ XANES are required. 
a)

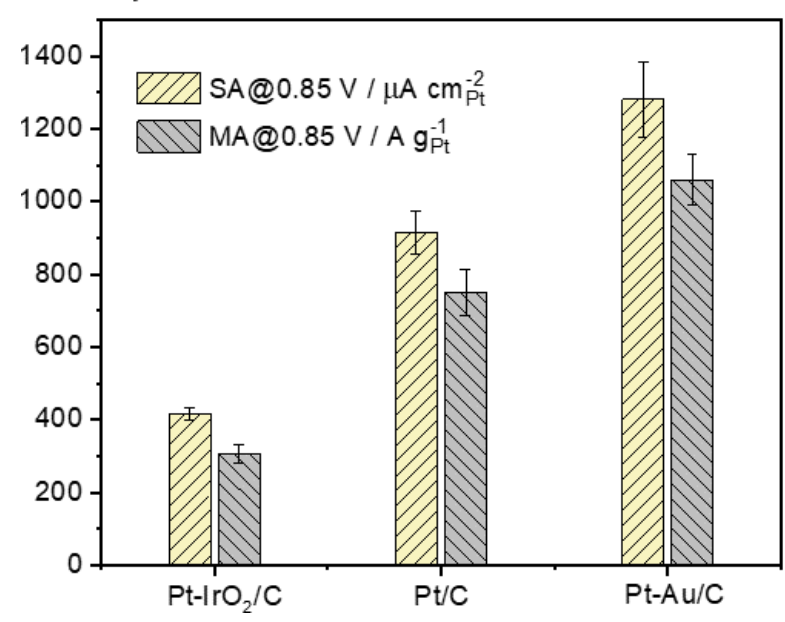

b)

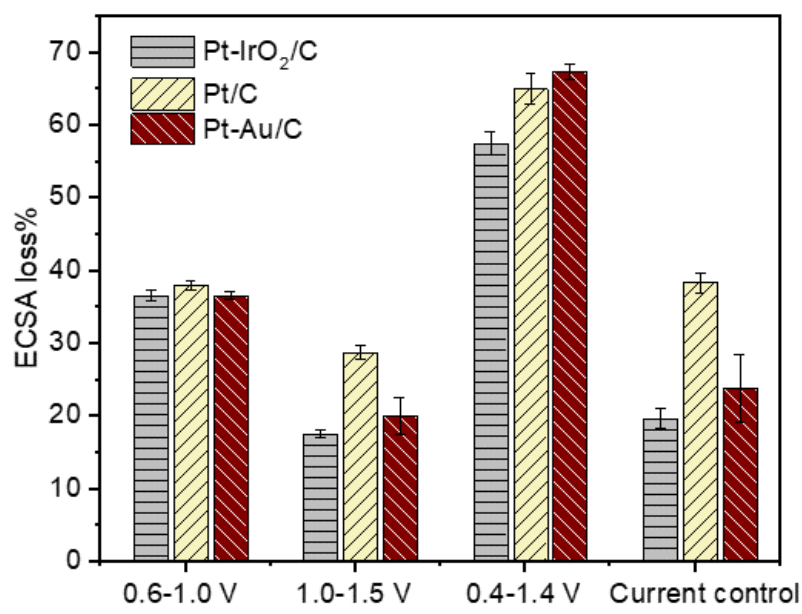

Figure 2. Comparison of the electrochemical performance of the supported monometallic $\mathrm{Pt}$ NPs and nanocomposite with RDE approach. a) ORR activity and b) stability is evaluated with four different degradation protocols. The data of the ECSA loss for the current control protocol applied to $\mathrm{Pt}-\mathrm{IrO}_{2} / \mathrm{C}$ and $\mathrm{Pt} / \mathrm{C}$ are taken from reference ${ }^{27}$. The ORR activity is determined from negative sweeping polarization curve at $0.85 \mathrm{~V}_{\mathrm{RHE}}$, a scan rate of $50 \mathrm{mV} \mathrm{s}^{-1}$ and a rotation speed of $1600 \mathrm{rpm}$ are applied in a potential region of $0.05-1.10 \mathrm{~V}_{\text {RHE }}$. The error is standard deviation from three independent measurements on each catalyst.

The trend in stability observed in the RDE measurements is less straightforward and depends on the applied ADT protocol. Based on literature and our previous work ${ }^{27,51}$, one might expect an improvement in stability when adding Ir NPs to the Pt/C benchmark catalyst. Such improvement is indeed observed, when choosing an ADT protocol that applies highly oxidizing conditions, see Figure 2. However, for simulated load cycle conditions no effect on the stability is detected. Furthermore, the effect in cycling stability (cycling the electrode potential between 0.40 and $1.40 \mathrm{~V}_{\mathrm{RHE}}$ with a scan rate of $1000 \mathrm{mV} \mathrm{s}^{-1}$ ) is only small. The findings for the Pt-Au/C nanocomposite are similar, i.e., a general improved stability is observed except that the cycling stability seems even slightly lower than for the Pt/C benchmark. The largest improvement in stability for the $\mathrm{Pt}-\mathrm{Au} / \mathrm{C}$ nanocomposite is an improvement by $38 \%$ as compared to the benchmark in the current control ADT, see also Figure $2 \mathrm{~b}$ and Table S4. In contrast to the Pt$\mathrm{IrO}_{2} / \mathrm{C}$ nanocomposite, the $\mathrm{Au} / \mathrm{Pt}$ ratio is not affected by the ADT treatment as shown by EDX analysis, see Figure S7. The analysis of the TEM micrographs of the degraded catalysts, 
displayed in Figure S7, clearly indicates particle growth, in particular in the $\mathrm{Pt} / \mathrm{C}$ benchmark catalyst.

Particle growth is normally associated with particle migration and coalescence and/or electrochemical Ostwald ripening ${ }^{52}$. However, it is difficult to distinguish between the two degradation mechanisms. In addition, carbon support oxidation occurs in cycling between oxidizing and reducing potentials ${ }^{53}$, which leads to Pt area loss due to particle loss. In Figure S7c and Figure S7g, a lower NP density on the support might indicate particle detachment, but it is difficult to exactly quantify the extent with conventional TEM.
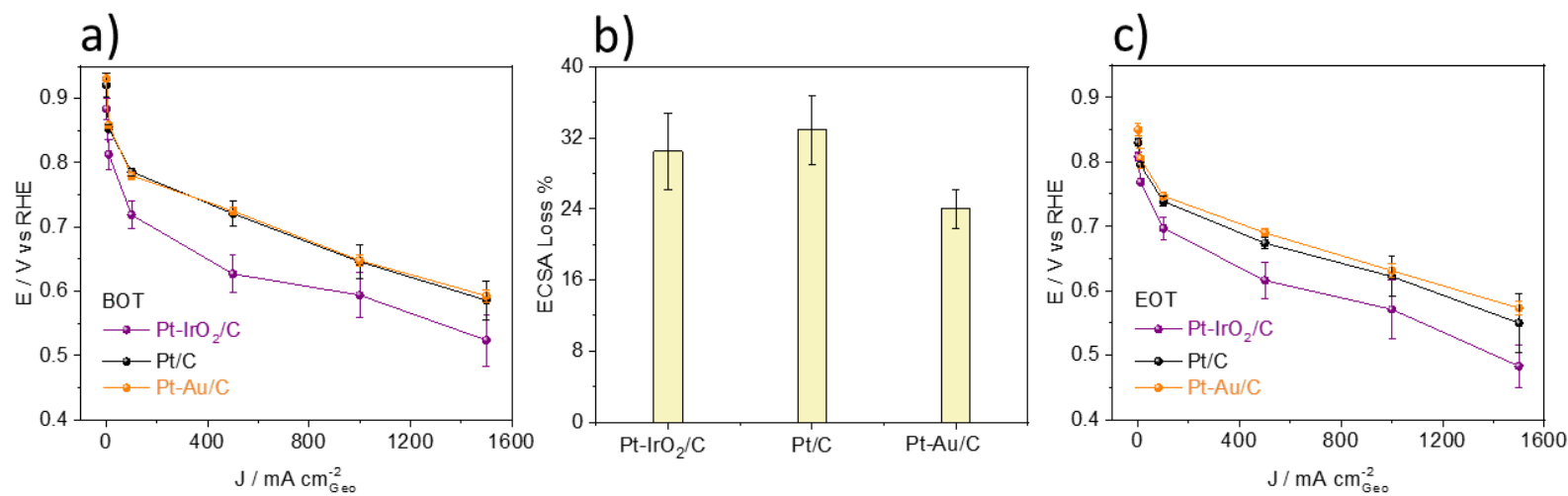

Figure 3. Comparison of the electrochemical performance of the supported monometallic $\mathrm{Pt}$ NPs and nanocomposite with GDE approach. a) ORR activity before degradation test, b) the loss in available Pt surface area and c) ORR activity after degradation test. The ORR activity is determined with current control mode, six constant current is applied on each measurement step for activity evaluation. The stability is determined in $\mathrm{O}_{2}$ atmosphere with a mixed degradation protocol of potential stepping between $0.60 \mathrm{~V}_{\mathrm{RHE}}$ and $1.00 \mathrm{~V}_{\mathrm{RHE}}$ followed by potential cycling between $1.00 \mathrm{~V}_{\mathrm{RHE}}$ and $1.50 \mathrm{~V}_{\mathrm{RHE}}$, the whole procedure is repeated for 20 times. The error is standard deviation from three independent measurements on each catalyst. BOT: before test, EOT: end of test.

As discussed in the introduction, the RDE technique is known for its simplicity and is widely used for fundamental research. The liquid electrolyte environment and low reactant mass transport however limit the extrapolation of the results to real devices ${ }^{54}$. Measurements in GDE setups combine the advantages of RDE with more realistic conditions close to the ones in membrane electrode assemblies (MEAs). Therefore, we compared the results of the RDE 
measurements to investigations performed in our recently developed GDE setup. All catalyst layers were prepared with a realistic Pt loading of $208 \mu \mathrm{g} \mathrm{cm}^{-2}$ geo on the GDL and the catalyst composition confirmed by EDX (the obtained metal compositions in wt.\% were $\mathrm{Ir} / \mathrm{Pt}=2.10$ and $\mathrm{Au} / \mathrm{Pt}=1.90$ for $\mathrm{Pt}-\mathrm{IrO}_{2} / \mathrm{C}$ and $\mathrm{Pt}-\mathrm{Au} / \mathrm{C}$; see also Table S5). The electrochemically active Pt area of each catalyst layer was determined in CO stripping measurements and presentative CO oxidation plots shown in Figure S4. It can be seen that the electrochemically active Pt area in all catalyst layers is similar and the performance of the different catalysts can be compared to each other.

The BOT ORR activity data are presented in Figure 3a, the respective Tafel plots (estimation) are shown in Figure S8 demonstrating that the Tafel slopes are basically consistent with the ones obtained in the RDE measurement. From the GDE data it is apparent that in agreement with the $\mathrm{RDE}$ data and as compared to the $\mathrm{Pt} / \mathrm{C}$ benchmark, the $\mathrm{Pt}-\mathrm{IrO}_{2} / \mathrm{C}$ nanocomposite exhibits indeed a substantially inhibited ORR performance over a wide range of current densities up to $1500 \mathrm{~mA} \mathrm{~cm}{ }^{-2} \mathrm{Geo}$. By comparison, the activity improvement $\mathrm{Pt}-\mathrm{Au} / \mathrm{C}$ nanocomposite is limited to very low current densities $\left(-1 \mathrm{~mA} \mathrm{~cm}_{\mathrm{geo}^{-2}}\right.$ and $\left.-10 \mathrm{~mA} \mathrm{~cm} \mathrm{geo}^{-2}\right)$ but at higher current densities, i.e., $\geq 100 \mathrm{~mA} \mathrm{~cm}^{-2}{ }_{\mathrm{Geo}}$, no improvement as compared to the $\mathrm{Pt} / \mathrm{C}$ benchmark is seen. Nevertheless, in Figure 5 it is demonstrated that at low current densities, i.e., high electrode potentials (here $0.85 \mathrm{~V}_{\mathrm{RHE}}$ ), the activity trends observed in the RDE and GDE are indeed comparable and consistent, although the absolute values differ.

The comparison between RDE and GDE therefore exemplifies the importance of performing measurements at realistic conditions as the improvement in kinetic ORR activity seen for the $\mathrm{Pt}-\mathrm{Au} / \mathrm{C}$ nanocomposite in the RDE measurements, can be confirmed in the GDE measurements, but at the same time it is highly unlikely that these improvements exhibit any relevance for conditions in applications. 

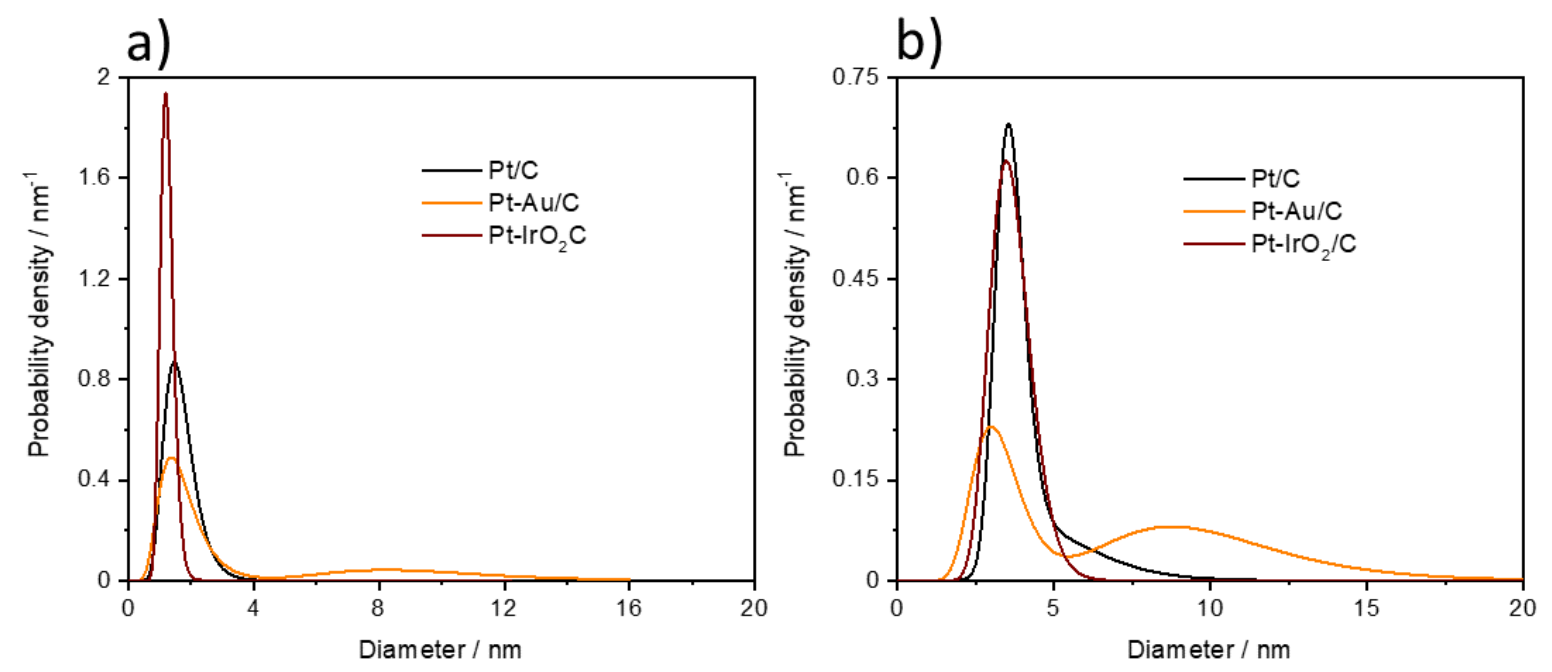

Figure 4. Particle size distributions, plotted as volume weighted probability density derived from SAXS analysis, of the investigated catalysts: (a) before and (b) after degradation test.

Performing the ADT and comparing the loss in Pt ECSA, the observed trends in stability are similar to the ones observed in the RDE measurements (the ADT consisted of a combination of load-cycle and start-stop simulation). However, one needs to keep in mind that the conditions in an aqueous electrolyte environment are different from those in a membrane electrolyte environment. For example, Ehelebe et al. recently reported that while Pt-ions can be transported away from a catalyst layer, the Pt dissolution rates in GDE experiments are considerably lower than in aqueous electrolyte environment; placing a membrane onto the catalyst layer reduced the dissolution rate even further ${ }^{25}$. In our study, both the $\mathrm{Pt}-\mathrm{IrO}_{2} / \mathrm{C}$ and $\mathrm{Pt}-\mathrm{Au} / \mathrm{C}$ nanocomposite exhibit improved stability as compared to the Pt/C benchmark (Figure 3b). A small difference exists, however, i.e., the Pt-Au/C nanocomposite appears to be slightly more stable than the Pt$\mathrm{IrO}_{2} / \mathrm{C}$ nanocomposite. Interestingly, the improved stability of the $\mathrm{Pt}-\mathrm{Au} / \mathrm{C}$ nanocomposite (as compared to $\mathrm{Pt} / \mathrm{C}$ ) results in a distinguishable improvement in the EOT ORR activity over the whole investigated current density range, see Figure 3c. By comparison, the improved stability of the Pt-IrO $\mathrm{I}_{2} / \mathrm{C}$ nanocomposite does not lead to any improved EOT ORR activity as compared to $\mathrm{Pt} / \mathrm{C}$. 
a)

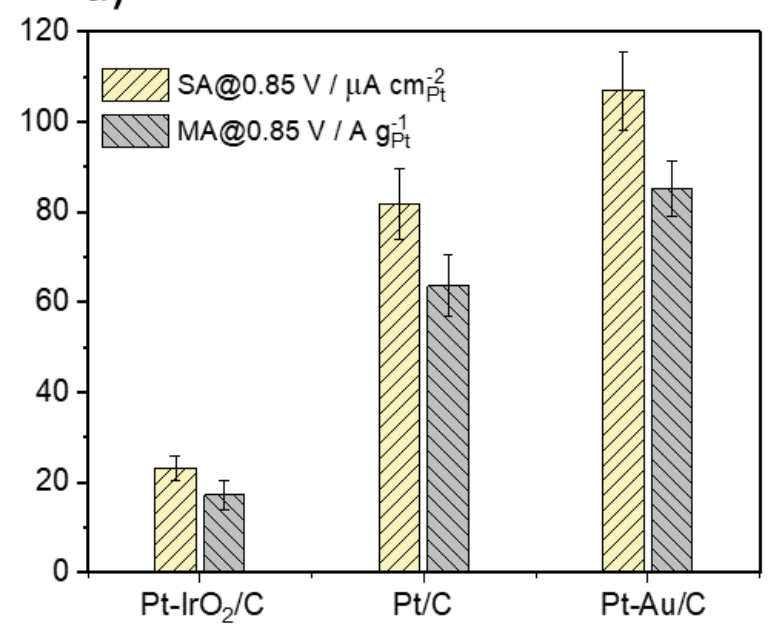

b)

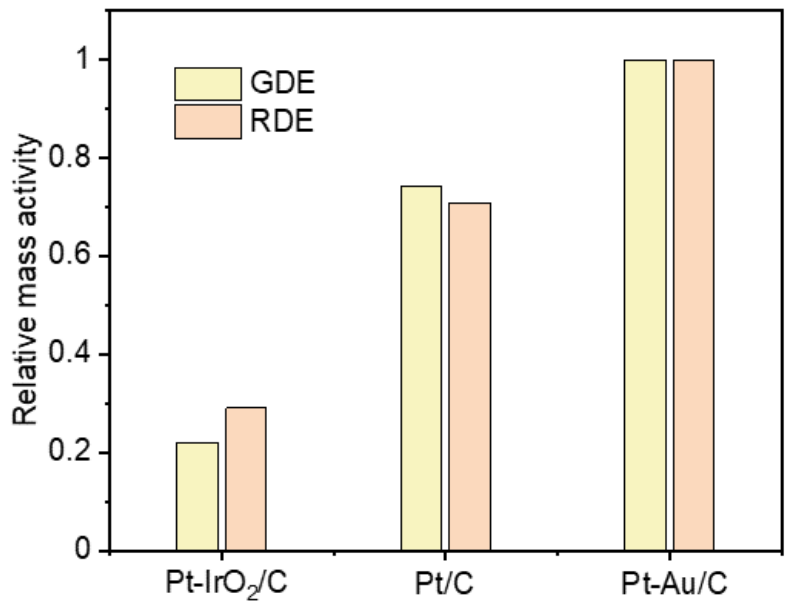

Figure 5. a) Comparison of the ORR activity at $0.85 \mathrm{~V}_{\mathrm{RHE}}$ determined with the GDE approach, b) comparison of the relative mass activity determined with GDE and RDE measurements, respectively. The SA and MA values at $0.85 \mathrm{~V}_{\mathrm{RHE}}$ from the GDE measurement are before degradation test and extracted from three independent measurements. For the relative mass activities, the activities are normalized to the one of Pt-Au/C. The activity determined by the RDE approach at $0.85 \mathrm{~V}_{\mathrm{RHE}}$ is determined from the negative going polarization curve.

In addition to more realistic reaction conditions, the GDE investigations also allow an ex situ analysis of the used (degraded) catalyst layers with SAXS ${ }^{24,29}$. Comparing the particle size distributions derived from SAXS at BOT and EOT indicates that the improved stability and ORR activity of the Pt-Au/C nanocomposite can be assigned to a reduced Pt particle growth, see Figure 4 and Table S2. A reduced particle growth in the Pt-Au/C nanocomposite as compared to the Pt/C benchmark is consistent with the lower loss in Pt ECSA and the less oxophilic nature of the Pt NPs adjacent to the Au NPs as discussed in RDE measurement section. Furthermore, a reduced particle growth is consistent with a reduced loss in oxygen transfer resistance at high current densities ${ }^{12}$. The weight ratio between Au and Pt thereby only changes slightly, i.e., from 1.90 to 1.80 (Table S5) indicating a low amount of Pt dissolution (or $\mathrm{Pt}$ and $\mathrm{Au}$ dissolve in equal amounts). Interestingly, in case of the $\mathrm{Pt}-\mathrm{IrO}_{2} / \mathrm{C}$ nanocomposite the improved stability is at the cost of a change in the Ir/Pt weight ratio which significantly decreases to a value of 0.99 (Table S5) indicating severe Ir dissolution during the ADT. 


\section{Conclusion}

In our study we compare the ORR performance (activity and stability) of two nanocomposite catalysts, i.e., $\mathrm{Pt}-\mathrm{IrO}_{2} / \mathrm{C}$ and $\mathrm{Pt}-\mathrm{Au} / \mathrm{C}$, to a $\mathrm{Pt} / \mathrm{C}$ benchmark. The $\mathrm{Pt}$ loading, $\mathrm{Pt}$ particle size and therefore the Pt ECSA in all catalysts could be kept constant. Comparing the performance with the state-of-the-art RDE approach it is concluded that both the introduction of $\mathrm{IrO}_{2}$ and $\mathrm{Au} \mathrm{NPs}$ to a Pt/C catalyst alleviates the degradation of the Pt NPs, the active phase for the ORR. In case of $\mathrm{IrO}_{2}$, however, the improvement in stability is at the expense of a decrease in ORR activity. By comparison, Au NPs seem to boost stability and ORR activity of the Pt NPs likewise. At conditions more closely comparable to MEAs, i.e., in a GDE setup, it is seen that the performance improvement of the $\mathrm{Pt}-\mathrm{Au} / \mathrm{C}$ nanocomposite is limited to very low current densities and cannot be sustained at high current density conditions most relevant for applications. Nevertheless, the Pt-Au/C nanocomposite offers a significant advantage that might be more realistically transferred to applications, i.e., its improved stability. The GDE measurements indicate that ultimately the improved stability might also lead to an improved ORR performance over the lifetime of the fuel cell. By comparison, the results indicate that stabilization of fuel catalysts by $\mathrm{IrO}_{2}$ might not be a promising approach as the stability improvement is at the expense of Ir dissolution and therefore more likely a short-term effect.

\section{Supporting information}

The supporting information contains additional experimental data. CVs, CO stripping curves, SAXS fits, Tafel plots, XANES spectra, degradation protocols, tables of particle size analysis from SAXS measurement, the specific and mass activities for ORR from RDE and GDE approach, ECSA values at beginning and end of the ADTs, a summary of the EDX data and TEM micrographs of the degraded catalyst with different protocols. 


\section{Acknowledgements}

This work was supported by the Swiss National Science Foundation (SNSF) via the project No. 200021_184742. Jia Du acknowledges funding from the China Scholarship Council (CSC). Jonathan Quinson acknowledges the European Union's Horizon 2020 research and innovation program under the Marie Skłodowska-Curie grant agreement No. 840523 (CoSolCat). S. B. Simonsen and L. Theil Kuhn, Technical University of Denmark, are thanked for access to TEM. The Niels Bohr Institute, Universtity of Copenhagen, for access to SAXS equipment and in particular J. K. K. Kirkensgaard. The authors thank Adam Clark from the SuperXAS beamline (X10DA) of the Swiss Light Source (SLS) for measuring and analyzing the XAS samples.

\section{References}

(1) Sievers, G. W. G. W.; Jensen, A. W. A. W.; Quinson, J.; Zana, A.; Bizzotto, F.; Oezaslan, M.; Dworzak, A.; Kirkensgaard, J. J. K. J. J. K.; Smitshuysen, T. E. L. T. E. L.; Kadkhodazadeh, S.; Juelsholt, M.; Jensen, K. M. Ø. K. M. Ø.; Anklam, K.; Wan, H.; Schäfer, J.; Čépe, K.; Escudero-Escribano, M.; Rossmeisl, J.; Quade, A.; Brüser, V.; Arenz, M. Self-Supported PtCoO Networks Combining High Specific Activity with High Surface Area for Oxygen Reduction. Nat. Mater. 2020. https://doi.org/10.1038/s41563-020-0775-8.

(2) Stamenkovic, V. R.; Mun, B. S.; Arenz, M.; Mayrhofer, K. J. J.; Lucas, C. A.; Wang, G.; Ross, P. N.; Markovic, N. M. Trends in Electrocatalysis on Extended and Nanoscale Pt-Bimetallic Alloy Surfaces. Nat. Mater. 2007, 6 (3). https://doi.org/10.1038/nmat1840.

(3) Chattot, R.; Le Bacq, O.; Beermann, V.; Kühl, S.; Herranz, J.; Henning, S.; Kühn, L.; Asset, T.; Guétaz, L.; Renou, G.; Drnec, J.; Bordet, P.; Pasturel, A.; Eychmüller, A.; Schmidt, T. J.; Strasser, P.; Dubau, L.; Maillard, F. Surface Distortion as a Unifying Concept and Descriptor in Oxygen Reduction Reaction Electrocatalysis. Nat. Mater. 2018. https://doi.org/10.1038/s41563-018-0133-2.

(4) Han, B.; Carlton, C. E.; Kongkanand, A.; Kukreja, R. S.; Theobald, B. R.; Gan, L.; O’Malley, R.; Strasser, P.; Wagner, F. T.; Shao-Horn, Y. Record Activity and Stability of Dealloyed 
Bimetallic Catalysts for Proton Exchange Membrane Fuel Cells. Energy Environ. Sci. 2015, 8 (1), 258-266. https://doi.org/10.1039/c4ee02144d.

(5) Stephens, I. E. L.; Bondarenko, A. S.; Grønbjerg, U.; Rossmeisl, J.; Chorkendorff, I. Understanding the Electrocatalysis of Oxygen Reduction on Platinum and Its Alloys. Energy and Environmental Science. 2012. https://doi.org/10.1039/c2ee03590a.

(6) Mayrhofer, K. J. J.; Hartl, K.; Juhart, V.; Arenz, M. Degradation of Carbon-Supported Pt Bimetallic Nanoparticles by Surface Segregation. J. Am. Chem. Soc. 2009, 131 (45). https://doi.org/10.1021/ja9074216.

(7) Batchelor, T. A. A.; Pedersen, J. K.; Winther, S. H.; Castelli, I. E.; Jacobsen, K. W.; Rossmeisl, J. High-Entropy Alloys as a Discovery Platform for Electrocatalysis. Joule 2019, 3 (3), 834845. https://doi.org/10.1016/j.joule.2018.12.015.

(8) Nesselberger, M.; Roefzaad, M.; Fayçal Hamou, R.; Ulrich Biedermann, P.; Schweinberger, F. F.; Kunz, S.; Schloegl, K.; Wiberg, G. K. H.; Ashton, S.; Heiz, U.; Mayrhofer, K. J. J.; Arenz, M. The Effect of Particle Proximity on the Oxygen Reduction Rate of Size-Selected Platinum Clusters. Nat. Mater. 2013, 12 (10). https://doi.org/10.1038/nmat3712.

(9) Speder, J.; Altmann, L.; Bäumer, M.; Kirkensgaard, J. J. K.; Mortensen, K.; Arenz, M. The Particle Proximity Effect: From Model to High Surface Area Fuel Cell Catalysts. RSC Adv. 2014, 4 (29). https://doi.org/10.1039/c4ra00261j.

(10) Huang, J.; Zhang, J.; Eikerling, M. H. Particle Proximity Effect in Nanoparticle Electrocatalysis: Surface Charging and Electrostatic Interactions. J. Phys. Chem. C 2017, 121 (9), 4806-4815. https://doi.org/10.1021/acs.jpcc.6b10842.

(11) Liu, H.; Mun, B. S.; Thornton, G.; Isaacs, S. R.; Shon, Y. S.; Ogletree, D. F.; Salmeron, M. Electronic Structure of Ensembles of Gold Nanoparticles: Size and Proximity Effects. Phys. Rev. B - Condens. Matter Mater. Phys. 2005, 72 (15), 1-5. https://doi.org/10.1103/PhysRevB.72.155430. 
(12) Kongkanand, A.; Mathias, M. F. The Priority and Challenge of High-Power Performance of Low-Platinum Proton-Exchange Membrane Fuel Cells. J. Phys. Chem. Lett. 2016, 7 (7), 11271137. https://doi.org/10.1021/acs.jpclett.6b00216.

(13) Kocha, S. S.; Shinozaki, K.; Zack, J. W.; Myers, D. J.; Kariuki, N. N.; Nowicki, T.; Stamenkovic, V.; Kang, Y.; Li, D.; Papageorgopoulos, D. Best Practices and Testing Protocols for Benchmarking ORR Activities of Fuel Cell Electrocatalysts Using Rotating Disk Electrode. Electrocatalysis 2017, 8 (4), 366-374. https://doi.org/10.1007/s12678-017-0378-6.

(14) Gasteiger, H. A.; Kocha, S. S.; Sompalli, B.; Wagner, F. T. Activity Benchmarks and Requirements for Pt, Pt-Alloy, and Non-Pt Oxygen Reduction Catalysts for PEMFCs. Applied Catalysis B: Environmental. 2005. https://doi.org/10.1016/j.apcatb.2004.06.021.

(15) Lopes, P. P.; Li, D.; Lv, H.; Wang, C.; Tripkovic, D.; Zhu, Y.; Schimmenti, R.; Daimon, H.; Kang, Y.; Snyder, J.; Becknell, N.; More, K. L.; Strmcnik, D.; Markovic, N. M.; Mavrikakis, M.; Stamenkovic, V. R. Eliminating Dissolution of Platinum-Based Electrocatalysts at the Atomic Scale. Nat. Mater. 2020. https://doi.org/10.1038/s41563-020-0735-3.

(16) Ioroi, T.; Yasuda, K. Platinum-Iridium Alloys as Oxygen Reduction Electrocatalysts for Polymer Electrolyte Fuel Cells. ECS Trans. 2019, 1 (6), 129-136. https://doi.org/10.1149/1.2214482.

(17) Inaba, M.; Quinson, J.; Arenz, M. PH Matters: The Influence of the Catalyst Ink on the Oxygen Reduction Activity Determined in Thin Film Rotating Disk Electrode Measurements. J. Power Sources 2017, 353, 19-27. https://doi.org/10.1016/j.jpowsour.2017.03.140.

(18) Inaba, M.; Quinson, J.; Bucher, J. R.; Arenz, M. On the Preparation and Testing of Fuel Cell Catalysts Using the Thin Film Rotating Disk Electrode Method. J. Vis. Exp. 2018, 2018 (133). https://doi.org/10.3791/57105.

(19) Wiberg, G. K. H. G. K. H.; Fleige, M.; Arenz, M. Gas Diffusion Electrode Setup for Catalyst Testing in Concentrated Phosphoric Acid at Elevated Temperatures. Rev. Sci. Instrum. 2015, 
86 (2). https://doi.org/10.1063/1.4908169.

(20) Pinaud, B. A.; Bonakdarpour, A.; Daniel, L.; Sharman, J.; Wilkinson, D. P. Key Considerations for High Current Fuel Cell Catalyst Testing in an Electrochemical Half-Cell. J. Electrochem. Soc. 2017. https://doi.org/10.1149/2.0891704jes.

(21) Ehelebe, K.; Seeberger, D.; Paul, M. T. Y.; Thiele, S.; Mayrhofer, K. J. J.; Cherevko, S. Evaluating Electrocatalysts at Relevant Currents in a Half-Cell: The Impact of Pt Loading on Oxygen Reduction Reaction. J. Electrochem. Soc. 2019, 166 (16), F1259-F1268. https://doi.org/10.1149/2.0911915jes.

(22) Inaba, M.; Jensen, A. W.; Sievers, G. W.; Escudero-Escribano, M.; Zana, A.; Arenz, M. Benchmarking High Surface Area Electrocatalysts in a Gas Diffusion Electrode: Measurement of Oxygen Reduction Activities under Realistic Conditions. Energy Environ. Sci. 2018, 11 (4), 988-994. https://doi.org/10.1039/C8EE00019K.

(23) Sievers, G. W.; Jensen, A. W.; Brüser, V.; Arenz, M.; Escudero-Escribano, M. Sputtered Platinum Thin-Films for Oxygen Reduction in Gas Diffusion Electrodes: A Model System for Studies under Realistic Reaction Conditions. Surfaces 2019, 2 (2), 336-348. https://doi.org/10.3390/surfaces2020025.

(24) Schröder, J.; Quinson, J.; Mathiesen, J. K.; Kirkensgaard, J. J. K.; Alinejad, S.; Mints, V. A.; Jensen, K. M. Ø.; Arenz, M. A New Approach to Probe the Degradation of Fuel Cell Catalysts under Realistic Conditions: Combining Tests in a Gas Diffusion Electrode Setup with Small Angle X-Ray Scattering. J. Electrochem. Soc. 2020. https://doi.org/10.1149/19457111/abbdd2.

(25) Ehelebe, K.; Knöppel, J.; Bierling, M.; Mayerhöfer, B.; Böhm, T.; Kulyk, N.; Thiele, S.; Mayrhofer, K.; Cherevko, S. Platinum Dissolution in Realistic Fuel Cell Catalyst Layers. Angew. Chemie Int. Ed. 2021. https://doi.org/10.1002/anie.202014711.

(26) Quinson, J.; Kunz, S.; Arenz, M. Beyond Active Site Design: A Surfactant-Free Toolbox 
Approach for Optimised Supported Nanoparticle Catalysts. ChemCatChem 2021, n/a (n/a). https://doi.org/https://doi.org/10.1002/cctc.202001858.

(27) Du, J.; Quinson, J.; Zhang, D.; Bizzotto, F.; Zana, A.; Arenz, M. Bifunctional Pt-IrO2 Catalysts for the Oxygen Evolution and Oxygen Reduction Reactions: Alloy Nanoparticles versus Nanocomposite Catalysts. ACS Catal. 2021, 11 (2), 820-828.

https://doi.org/10.1021/acscatal.0c03867.

(28) Zhang, Z.; Xin, L.; Qi, J.; Wang, Z.; Li, W. Selective Electro-Conversion of Glycerol to Glycolate on Carbon Nanotube Supported Gold Catalyst. Green Chem. 2012, 14 (8), 21502152. https://doi.org/10.1039/C2GC35505A.

(29) Alinejad, S.; Quinson, J.; Schröder, J. J.; Kirkensgaard, J. J. K.; Arenz, M. Carbon-Supported Platinum Electrocatalysts Probed in a Gas Diffusion Setup with Alkaline Environment: How Particle Size and Mesoscopic Environment Influence the Degradation Mechanism. ACS Catal. 2020. https://doi.org/10.1021/acscatal.0c03184.

(30) Yarlagadda, V.; McKinney, S. E.; Keary, C. L.; Thompson, L.; Zulevi, B.; Kongkanand, A. Preparation of PEMFC Electrodes from Milligram-Amounts of Catalyst Powder. $J$. Electrochem. Soc. 2017, 164 (7), F845-F849. https://doi.org/10.1149/2.1461707jes.

(31) Bizzotto, F.; Quinson, J.; Zana, A.; Kirkensgaard, J. J. K.; Dworzak, A.; Oezaslan, M.; Arenz, M. Ir Nanoparticles with Ultrahigh Dispersion as Oxygen Evolution Reaction (OER) Catalyst: Synthesis and Activity Benchmarking. Catal. Sci. Technol. 2019, 6345-6356. https://doi.org/10.1039/c9cy01728c.

(32) Ohma, A.; Shinohara, K.; Iiyama, A.; Yoshida, T.; Daimaru, A. Membrane and Catalyst Performance Targets for Automotive Fuel Cells by FCCJ Membrane, Catalyst, MEA WG. ECS Trans. 2019, 41 (1), 775-784. https://doi.org/10.1149/1.3635611.

(33) Pizzutilo, E.; Geiger, S.; Grote, J.-P.; Mingers, A.; Mayrhofer, K. J. J.; Arenz, M.; Cherevko, S. On the Need of Improved Accelerated Degradation Protocols (ADPs): Examination of 
Platinum Dissolution and Carbon Corrosion in Half-Cell Tests. J. Electrochem. Soc. 2016, 163 (14). https://doi.org/10.1149/2.0731614jes.

(34) Mayrhofer, K. J. J. K. J. J.; Meier, J. C. J. C.; Ashton, S. J. S. J.; Wiberg, G. K. H. G. K. H.; Kraus, F.; Hanzlik, M.; Arenz, M. Fuel Cell Catalyst Degradation on the Nanoscale. Electrochem. commun. 2008, 10 (8), 1144-1147. https://doi.org/10.1016/j.elecom.2008.05.032.

(35) Alinejad, S.; Inaba, M.; Schröder, J.; Du, J.; Quinson, J.; Zana, A.; Arenz, M. Testing Fuel Cell Catalysts under More Realistic Reaction Conditions: Accelerated Stress Tests in a Gas Diffusion Electrode Setup. J. Phys. Energy 2020, 2 (2), 024003. https://doi.org/10.1088/25157655/ab67e2.

(36) Müller, O.; Nachtegaal, M.; Just, J.; Lützenkirchen-Hecht, D.; Frahm, R. Quick-EXAFS Setup at the SuperXAS Beamline for in Situ X-Ray Absorption Spectroscopy with 10ms Time Resolution. J. Synchrotron Radiat. 2016, 23, 260-266. https://doi.org/10.1107/S1600577515018007.

(37) Clark, A. H.; Imbao, J.; Frahm, R.; Nachtegaal, M. ProQEXAFS: A Highly Optimized Parallelized Rapid Processing Software for QEXAFS Data. J. Synchrotron Radiat. 2020, 27, 551-557. https://doi.org/10.1107/S1600577519017053.

(38) Kodama, K.; Shinohara, A.; Hasegawa, N.; Shinozaki, K.; Jinnouchi, R.; Suzuki, T.; Hatanaka, T.; Morimoto, Y. Catalyst Poisoning Property of Sulfonimide Acid Ionomer on Pt (111) Surface. J. Electrochem. Soc. 2014, 161 (5), F649-F652. https://doi.org/10.1149/2.051405jes.

(39) Jusys, Z.; Behm, R. J. The Effect of Anions and PH on the Activity and Selectivity of an Annealed Polycrystalline Au Film Electrode in the Oxygen Reduction Reaction-Revisited. ChemPhysChem 2019. https://doi.org/10.1002/cphc.201900960.

(40) Ohta, N.; Nomura, K.; Yagi, I. Adsorption and Electroreduction of Oxygen on Gold in Acidic Media: In Situ Spectroscopic Identification of Adsorbed Molecular Oxygen and Hydrogen Superoxide. J. Phys. Chem. C 2012. https://doi.org/10.1021/jp302857q. 
(41) Wang, Y.; Laborda, E.; Ward, K. R.; Tschulik, K.; Compton, R. G. A Kinetic Study of Oxygen Reduction Reaction and Characterization on Electrodeposited Gold Nanoparticles of Diameter between $17 \mathrm{Nm}$ and $40 \mathrm{Nm}$ in $0.5 \mathrm{M}$ Sulfuric Acid. Nanoscale 2013. https://doi.org/10.1039/c3nr02340k.

(42) Chung, D. Y.; Park, S.; Lee, H.; Kim, H.; Chung, Y.-H.; Yoo, J. M.; Ahn, D.; Yu, S.-H.; Lee, K.-S.; Ahmadi, M.; Ju, H.; Abruña, H. D.; Yoo, S. J.; Mun, B. S.; Sung, Y.-E. ActivityStability Relationship in Au@Pt Nanoparticles for Electrocatalysis. ACS Energy Lett. 2020, 2827-2834. https://doi.org/10.1021/acsenergylett.0c01507.

(43) Kodama, K.; Jinnouchi, R.; Takahashi, N.; Murata, H.; Morimoto, Y. Activities and Stabilities of Au-Modified Stepped-Pt Single-Crystal Electrodes as Model Cathode Catalysts in Polymer Electrolyte Fuel Cells. J. Am. Chem. Soc. 2016, 138 (12), 4194-4200. https://doi.org/10.1021/jacs.6b00359.

(44) Uribe, F. A.; Zawodzinski, T. A. A Study of Polymer Electrolyte Fuel Cell Performance at High Voltages. Dependence on Cathode Catalyst Layer Composition and on Voltage Conditioning. Electrochim. Acta 2002, 47 (22-23), 3799-3806. https://doi.org/10.1016/S00134686(02)00350-X.

(45) Pašti, I. A.; Gavrilov, N. M.; Mentus, S. V. Electrocatalytic Behavior of Pt/WO3 Composite Layers Formed Potentiodynamically on Tungsten Surfaces. Int. J. Electrochem. Sci. 2017, 12 (6), 5772-5791. https://doi.org/10.20964/2017.06.80.

(46) Wiberg, G. K. H.; Arenz, M. Establishing the Potential Dependent Equilibrium Oxide Coverage on Platinum in Alkaline Solution and Its Influence on the Oxygen Reduction. $J$. Power Sources 2012, 217. https://doi.org/10.1016/j.jpowsour.2012.06.019.

(47) Hodnik, N.; Baldizzone, C.; Cherevko, S.; Zeradjanin, A.; Mayrhofer, K. J. J. The Effect of the Voltage Scan Rate on the Determination of the Oxygen Reduction Activity of Pt/C Fuel Cell Catalyst. Electrocatalysis 2015, 6 (3), 237-241. https://doi.org/10.1007/s12678-015-0255-0. 
(48) Shinozaki, K.; Zack, J. W.; Richards, R. M.; Pivovar, B. S.; Kocha, S. S. Oxygen Reduction Reaction Measurements on Platinum Electrocatalysts Utilizing Rotating Disk Electrode Technique: I. Impact of Impurities, Measurement Protocols and Applied Corrections. $J$. Electrochem. Soc. 2015. https://doi.org/10.1149/2.1071509jes.

(49) Nørskov, J. K.; Rossmeisl, J.; Logadottir, A.; Lindqvist, L.; Kitchin, J. R.; Bligaard, T.; Jónsson, H. Origin of the Overpotential for Oxygen Reduction at a Fuel-Cell Cathode. J. Phys. Chem. B 2004. https://doi.org/10.1021/jp047349j.

(50) Teliska, M.; Murthi, V. S.; Mukerjee, S.; Ramaker, D. E. Correlation of Water Activation, Surface Properties, and Oxygen Reduction Reactivity of Supported Pt-M/C Bimetallic Electrocatalysts Using XAS. J. Electrochem. Soc. 2005, 152 (11), A2159. https://doi.org/10.1149/1.2040949.

(51) Crowtz, T. C.; Dahn, J. R. Screening Bifunctional Pt Based NSTF Catalysts for Durability with the Rotating Disk Electrode: The Effect of Ir and Ru. J. Electrochem. Soc. 2018. https://doi.org/10.1149/2.0891810jes.

(52) Schlögl, K.; Hanzlik, M.; Arenz, M. Comparative IL-TEM Study Concerning the Degradation of Carbon Supported Pt-Based Electrocatalysts. J. Electrochem. Soc. 2012. https://doi.org/10.1149/2.035206jes.

(53) Ashton, S. J.; Arenz, M. A DEMS Study on the Electrochemical Oxidation of a High Surface Area Carbon Black. Electrochem. commun. 2011, 13 (12). https://doi.org/10.1016/j.elecom.2011.09.024.

(54) Kodama, K.; Nagai, T.; Kuwaki, A.; Jinnouchi, R.; Morimoto, Y. Challenges in Applying Highly Active Pt-Based Nanostructured Catalysts for Oxygen Reduction Reactions to Fuel Cell Vehicles. Nat. Nanotechnol. 2021. https://doi.org/10.1038/s41565-020-00824-w. 